\title{
Designs I Subtest (WMS-IV)
}

National Cancer Institute

\section{Source}

National Cancer Institute. Designs I Subtest (WMS-IV). NCI Thesaurus. Code C120346.

A subtest of the Wechsler Memory Scale, 4th Edition that evaluates immediate recall. The subject is shown a grid with 4-8 designs on a page for 10 seconds, which is then removed from view. The subject then selects the designs from a set of cards and places the cards in a grid in the same place as previously shown. 